\section{BEAUTIFULLY PRESENTED AND SUPPLIED}

WhiteWash Laboratories is now working with CTS Dental Supplies - the UK's expert oral hygiene suppliers.

By combining WhiteWash's premium product range with CTS's outstanding service record and long experience in the industry, practices can benefit from the very best oral hygiene products offered at extremely

\section{$\longrightarrow$ competitive prices.}

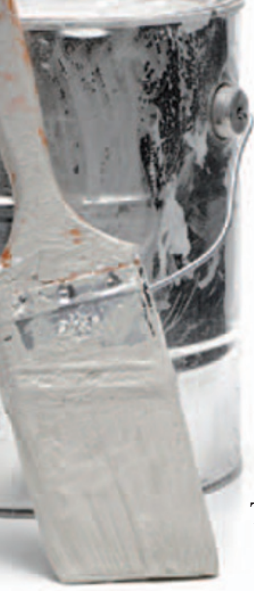

With a focus on innovation and quality, WhiteWash is committed to providing exceptional oral healthcare products that are beautifully presented and offer outstanding premium features. These products include:

- Professional Whitening Toothpaste - complete with special micro-polishers to help brighten teeth and restore natural whiteness. Also includes Aloe Vera, Green Tea Extract, and Vitamin E

- Nano-Silver Whitening Toothbrush - with special duallayered whitening bristles and unique anti-bacterial properties

- Professional Teeth Whitening Strips - containing an advanced formula with slow-release whitening ingredients for a more effective whitening result.

All of WhiteWash's products have been developed and formulated by UK dentists.

For more information call 08446869150 or visit www. whitewashlaboratories.com.

\section{MORE ACCURATE, LESS RADIATION}

The first Morita Veraviewepocs 3D R100 cone beam tomography scanner in the UK is already helping to provide accurate treatment planning with lower X-ray dosage. With up to three times the image detail of other 3D X-ray systems, the Morita R100 offers the best value in the UK in terms of resolution and capital cost.

Capturing posterior dentition missed by an $80 \mathrm{~mm}$ diameter field of view (FOV), the R100 field includes relevant anatomy equivalent to a $100 \mathrm{~mm}$ cylindrical scan. By closely matching the natural dental arch, the revolutionary Reuleaux triangle full arch FOV reduces patient X-ray dosage by around 15\%, compared with a $100 \mathrm{~mm}$ scan. provides five smaller fields of view down to just $40 \mathrm{~mm}$ diameter. This allows the operator to optimise the size of the $3 \mathrm{D}$ scan to the required anatomy while reducing X-ray dosage.

For your FREE demonstration call 08453883380 or email info@morita-uk.com.
The same machine also

\section{REMOVING MONETARY STRESSES AND STRAINS}

The team at Henry Schein Minerva are highly knowledgeable and experienced in offering the best, most practical advice on how to grow and improve your practice within your budget. Henry Schein Financial Services options are tailored to meet your individual needs.

Henry Schein Financial Services has been created to present options that may not have been possible before and will help practices manage finances and fund practice growth, with solutions for leasing, lease purchasing, hire purchase and borrowing issues for everything from equipment and merchandise to computer hardware/ software, and even building and commissioning services. This coupled with extremely competitive rates means that better, more advanced equipment can be readily available without additional monetary stresses and strains.

To find out more call a highly experienced consultant on 08700102120 or visit www.henryschein.co.uk.

\section{SIMPLE, SMART, SHARP PHOTOGRAPHY}

The Digital Doc Iris from Digital Dental combines brilliance with beauty and is the latest advance in intraoral cameras because it is simpler, smarter and sharper.

The high quality Iris digital intraoral camera enables dental professionals to communicate better to increase acceptance for their treatment plans. Simply use the 5-point Focus Wheel for superb

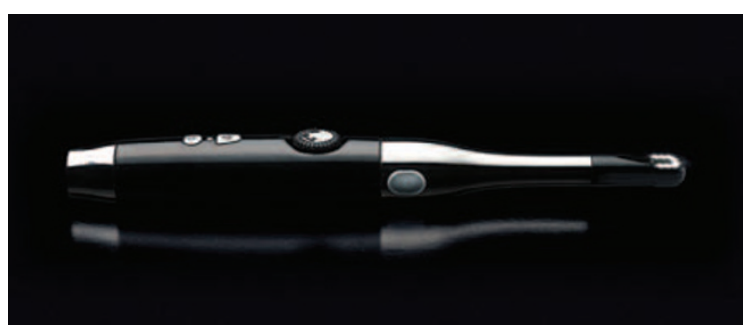

crystal clear high magnification intraoral images. Similarly, its small soft-tip, with brilliant automatic eight-point LED lighting, makes it even easier to take good close up images of posterior teeth. Combined with the new bright Glo True Spectrum LED light it also enables clinicians to quickly capture full face, full smile, upper and lower arch shots in sparkling colour and sharp detail.

The robust and easily portable Iris is no bigger than an electric toothbrush and fits any PC. It can also be fitted to any dental unit and integrates with any dental imaging software. Combine the camera with a ceiling mounted display for the perfect patient communication and entertainment system.

Digital Dental has installed over one thousand of these systems, so can demonstrate how to quickly and easily use Iris to get the best images possible and a speedy return on investment.

For further information telephone Digital Dental on 0800027 8393, email sales@ digitaldental.co.uk or visit www. digitaldental.co.uk. 